\title{
Preparation of novolac-type phenol-based activated carbon with a hierarchical pore structure and its electric double-layer capacitor performance
}

\author{
Dayoung Lee, Jin-Young Jung, Mi-Seon Park and Young-Seak Lee \\ Department of Applied Chemistry and Biological Engineering, Chungnam National University, Daejeon 305-764, Korea
}

\author{
Article Info \\ Received 21 April 2014 \\ Accepted 2 June 2014 \\ *Corresponding Author \\ E-mail: youngslee@cnu.ac.kr
}

\section{Open Access}

DOI: http://dx.doi.org/

10.5714/CL.2014.15.3.192

This is an Open Access article distributed under the terms of the Creative Commons Attribution Non-Commercial License (http://creativecommons.org/licenses/ by-nc/3.0/) which permits unrestricted non-commercial use, distribution, and reproduction in any medium, provided the original work is properly cited.

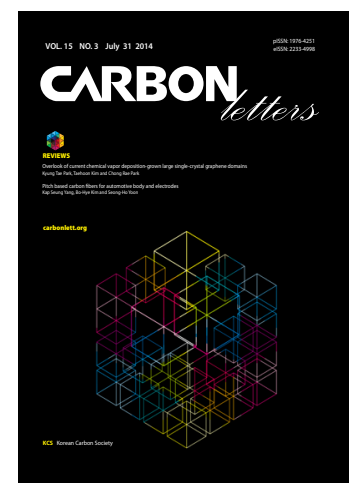

http://carbonlett.org

pISSN: $1976-4251$

elSSN: 2233-4998

Copyright $\odot$ Korean Carbon Society

\begin{abstract}
A hierarchical pore structured novolac-type phenol based-activated carbon with micropores and mesopores was fabricated. Physical activation using a sacrificial silicon dioxide $\left(\mathrm{SiO}_{2}\right)$ template and chemical activation using potassium hydroxide $(\mathrm{KOH})$ were employed to prepare these materials. The morphology of the well-developed pore structure was characterized using field-emission scanning electron microscopy. The novolac-type phenol-based activated carbon retained hierarchical pores (micropores and mesopores); it exhibited high Brunauer-Emmett-Teller specific surface areas and hierarchical pore size distributions. The hierarchical pore novolac-type phenol-based activated carbon was used as an electrode in electric double-layer capacitors, and the specific capacitance and the retained capacitance ratio were measured. The specific capacitances and the retained capacitance ratio were enhanced, depending on the $\mathrm{SiO}_{2}$ concentration in the material. This result is attributed to the hierarchical pore structure of the novolac-type phenol-based activated carbon.
\end{abstract}

Key words: activated carbon, Brunauer-Emmett-Teller surface area, electrodes, porosity, scanning electron microscopy

\section{Introduction}

Various energy storage devices have been developed to address the pressing demand for high-energy, high-power-density and long-life energy storage devices for applications ranging from portable electronics to biomedical devices to hybrid electric vehicles. Among these devices, electrochemical double-layer capacitors (EDLCs), commonly known as super-capacitors, have emerged as a promising energy storage option for applications that require high power along with exceptional storage and cycle lives [1].

Carbonaceous materials are a practical electrode material for EDLCs because of their high specific surface area, proper pore size distribution, good electronic conductivity, good chemical stability, low cost of economic production, and easily tuned morphology and porosity $[2,3]$. The porous properties of activated carbons are well known to strongly depend on the structure of their precursor (Bansal et al., 1988). Phenolic resin is one of the most commonly used synthetic precursors for the production of activated carbons. Although many researchers have reported that various types of activated carbons can be prepared from various types of phenolic resins, the obtained activated carbons are mostly microporous (Lenghous et al., 2002; Centeno and Fuerted, 1999; Tennison, 1998; Mangun et al., 1998; Daley et al., 1997) [4].

However, the micropores of activated carbons limit accessibility to electrolytes during the charge/discharge process and are disadvantageous for ion diffusion, particularly under highloading current-density conditions. Moreover, the mesopores of the activated carbons have a relatively low specific surface area, accompanied by low capacitance. For these reasons, the synthesis of hierarchical-porous carbon with both micropores and mesopores is important 
for EDLC performance because micropores and mesopores are complementary $[5,6]$.

The template technique is an important method for achieving various pore sizes and structures in the micropore to macropore range and is typically accomplished by changing the template of the carbon precursor. Importantly, silicon dioxide $\left(\mathrm{SiO}_{2}\right)$ acts as a physical template to control the size and morphology of the final product and leaves no trace such as the chemical composition in the final product. Additionally, $\mathrm{SiO}_{2}$ and be used to aid in the manufacture of mesoporous carbon by acting as a $\mathrm{SiO}_{2}$ template $[7,8]$.

In the present study, pore control of novolac-type phenolbased activated carbon with a hierarchical pore structure (micropores and mesopores) was improved using a $\mathrm{SiO}_{2}$ template with different $\mathrm{SiO}_{2}$ :novolac resin weight ratios for physical activation and $4 \mathrm{M}$ potassium hydroxide $(\mathrm{KOH})$ as an chemical activating agent. The effects of physical and chemical activation on the surface morphology and textural properties of the novolac-type phenol-based activated carbon were investigated, and products were evaluated as potential electrode materials in EDLCs.

\section{Experimental}

\subsection{Materials}

Novolac (phenol formaldehyde resin, KPH-F2004, Kolon) was melted in an organic solvent such as alcohol or acetone. Because novolac has a linear structure that consists of linked methylene groups $\left(-\mathrm{CH}_{2}-\right)$, methanol (methyl alcohol, Samchun) was used as the solvent for mixing novolac and $\mathrm{SiO}_{2}$ (Degussa, R972, average size $=16 \pm 2 \mathrm{~nm}$ ). To generate mesoporous carbon materials, $\mathrm{SiO}_{2}$ was used as the template for physical activation and hydrofluoric (HF acid, 48.0\%-51.0\%, J.T Baker) was used for silica removal. Additionally, chemical activation was performed using KOH (95.0\%, Samchun) to obtain microporous carbon materials.

\subsection{Preparation of silica-embedded novolac solution}

The $\mathrm{SiO}_{2}$ and novolac dissolved in methanol were mixed with an internal mixer at $45^{\circ} \mathrm{C}$ until entirely melted and homogenized. Sonication was used to disperse $\mathrm{SiO}_{2}$ within the melted solution. The $\mathrm{SiO}_{2}$ recruitment stock was 5, 15, and $30 \mathrm{wt} \%$ compared to novolac.

\subsection{Heat treatment}

Before carbonization, the mixture solution of $\mathrm{SiO}_{2}$, novolac, and methanol was cured at $150^{\circ} \mathrm{C}$ for $4 \mathrm{~h}$ under air. Consequently, cured samples of materials that had originally exhibited thermoplastic characteristics now exhibited thermosetting characteristics. The heating rate was $1{ }^{\circ} \mathrm{C} / \mathrm{min}$ during this step. The cured samples were subsequently carbonized under a nitrogen atmosphere at $1050^{\circ} \mathrm{C}$ for $1 \mathrm{~h}$. During this step, the heating rate was $5^{\circ} \mathrm{C} / \mathrm{min}$.

\subsection{HF treatment}

To form mesoporous novolac-type phenol based carbon, carbonized products were soaked in HF for $24 \mathrm{~h}$ and washed with distilled water several times. Finally, each sample was dried at $120^{\circ} \mathrm{C}$ overnight. During this process, $\mathrm{SiO}_{2}$ in the novolac was removed via the reaction:

$$
\mathrm{SiO}_{2}+4 \mathrm{HF} \rightarrow \mathrm{SiF}_{4}+2 \mathrm{H}_{2} \mathrm{O}
$$

\subsection{Chemical activation using $\mathrm{KOH}$}

A hierarchical porous novolac-type phenol based-activated carbon materials were prepared from the mesoporous carbon materials using $\mathrm{KOH}$. We chemically activated the mesoporous phenol-based carbons by dipping $1 \mathrm{~g}$ of each sample in $20 \mathrm{~mL}$ of $4 \mathrm{M} \mathrm{KOH}$ for $4 \mathrm{~h}$. The mesoporous phenol-based carbons in this $\mathrm{KOH}$ solution were subsequently treated at high temperatures under flowing nitrogen. The temperature during this process was maintained at $750^{\circ} \mathrm{C}$ for $3 \mathrm{~h}$. After chemical activation, the resulting carbon samples were washed with distilled water to remove residual potassium and dried at $120^{\circ} \mathrm{C}$ overnight.

The carbonized phenol-based carbon and hierarchical-porous (micropores and mesopores) structured materials were prepared using various weight ratios of $\mathrm{SiO}_{2}$ template $(0,5$, 15 , and $30 \mathrm{wt} \%$ ) relative to novolac as follows: $\mathrm{CN}, 5 \mathrm{SNK}$, $15 \mathrm{SNK}$, and 30SNK.

\subsection{Characterization of phenol-based activated carbon materials with hierarchical-pore (micropores and mesopores) structure}

The surface morphology of developed hierarchical porestructured carbon materials were investigated using field emission scanning electron microscopy (FE-SEM; Hitachi, S-5500, KBSI).

The textural properties of the prepared samples were also investigated. Each sample was degassed at $150^{\circ} \mathrm{C}$ for $180 \mathrm{~min}$, and nitrogen adsorption was conducted at $77 \mathrm{~K}$ using a Micromeritics ASAP 2020 volumetric adsorption apparatus to study the pore characteristics such as specific surface area, total pore volume, and pore size distribution.

For the preparation of EDLC electrodes, $80 \mathrm{wt} \%$ prepared samples, $10 \mathrm{wt} \%$ carbon black (Super P; Timcal Ltd., Switzerland), and a $10 \mathrm{wt} \%$ solution of polyvinylidene fluoride (PVDF; Aldrich, USA) were mixed in N-methyl pyrrolidone (NMP; Aldrich, USA) to form a slurry. The slurry was subsequently painted onto a titanium plate. Electrochemical characterization of the hierarchical pore structured (micropores and mesopores) phenol-based carbon was conducted with a computer-controlled potentiostat-galvanostat (Ivium Technologies, The Netherlands) using a three-electrode assembly.

In the three-electrode assembly, the hierarchical porous phenol-based carbon, a $\mathrm{Ag} / \mathrm{AgCl}$ electrode, and a platinum plate were used as the working, reference, and counter electrodes, respectively. In addition, cyclic voltammetry $(\mathrm{CV})$ was performed over a potential range of $0-1 \mathrm{~V}$ at a scan rate of 5 and $50 \mathrm{mV} / \mathrm{s}$; $1 \mathrm{M} \mathrm{H}_{2} \mathrm{SO}_{4}$ was used as the electrolyte for the electrochemical measurements. 


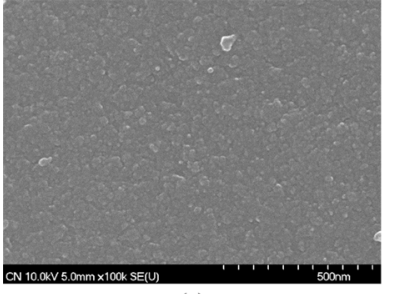

(a)

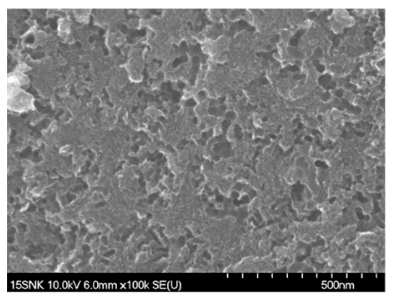

(c)

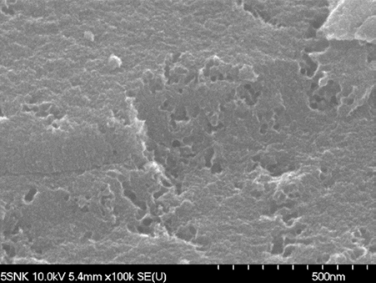

(b)

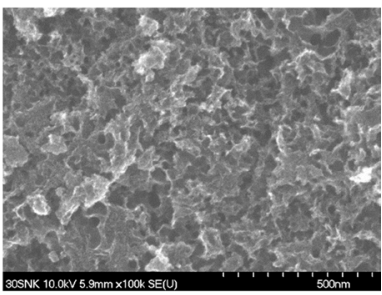

(d)
Fig. 1. Scanning electron microscopy images of the phenol-based carbons before and after activation: (a) CN; (b) 5SNK; (c) 15SNK; (d) 30SNK.

\section{Results and Discussion}

\subsection{Surface morphology of phenol-based activated carbon with hierarchical pore structure}

To examine the surface morphology, carbonized phenolbased carbon and hierarchical porous phenol-based carbon were studied by SEM. As shown in Fig. 1, pores with different sizes and different morphologies existed within the structure of the prepared samples. Chemical activation with $\mathrm{KOH}$ influenced the surface roughness of the carbon materials as a consequence of reactions between the carbon surface and $\mathrm{KOH}$. Surface carbon was consumed while pores were developed by opening previously closed surface pores during the gasification process [9-11]. The increase in surface roughness was confirmed to result in chemical activation, as shown in Figs. 1a and b. In addition, Figs. $1 \mathrm{~b}$ and d present SEM images of the physical and chemical activated carbons prepared using different amounts of the $\mathrm{SiO}_{2}$ template. After the $\mathrm{HF}$ treatment, the $\mathrm{SiO}_{2}$ template formed around openings of a fixed size, comparatively. The portion of round openings broadened with increasing quantity of $\mathrm{SiO}_{2}$. The surface roughness of 30SNK, in particular, almost completely disappeared.

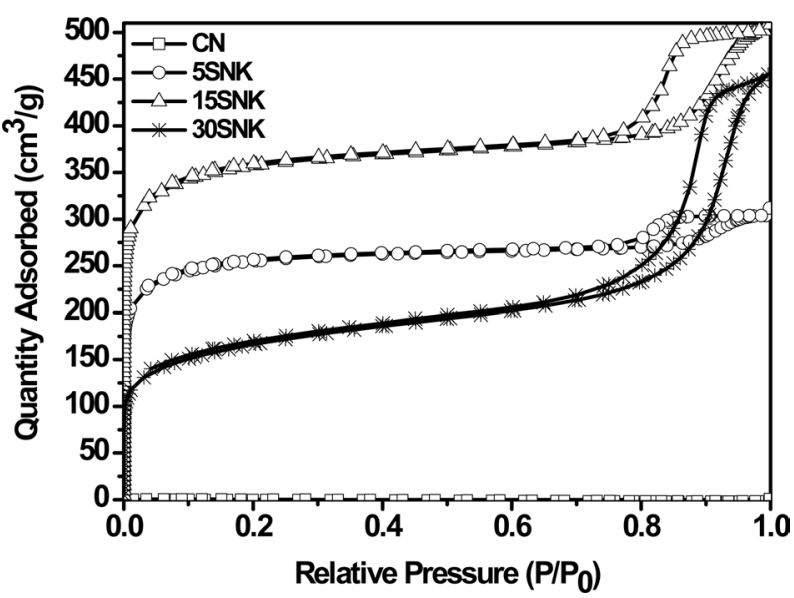

Fig. 2. $\mathrm{N}_{2}$ adsorption-desorption isotherms of novolac-type phenolbased activated carbons at $-196.15^{\circ} \mathrm{C}$.

\subsection{Textural properties of phenol-based ac- tivated carbon with hierarchical pore structure}

Fig. 2 shows nitrogen sorption isotherms of the carbonized carbon and physically/chemically activated carbon; the sorption measurements were performed at $77 \mathrm{~K}$. On the basis of the International Union of Pure and Applied Chemistry (IUPAC) classification scheme, the isotherm of the physically/chemically activated carbon was Type IV $[12,13]$. The activated carbon samples exhibited a dramatic increase in the quantity of nitrogen adsorbed below $0.01 \mathrm{P} / \mathrm{P}_{0}$, indicating the development of a microporous structure; this effect was most pronounced in the case of $15 \mathrm{SNK}$ [14-16]. The isotherms of the activated carbon increased markedly below $0.1 \mathrm{P} / \mathrm{P}_{0}$ and then increased slowly above $0.1 \mathrm{P} / \mathrm{P}_{0}$, indicating the development of micropores and some mesopores in the activated carbon due to chemical activation by $\mathrm{KOH}$ and physical activation by the $\mathrm{SiO}_{2}$ template, respectively. Hysteresis loops were observed in the cases of $5 \mathrm{SNK}, 15 \mathrm{SNK}$, and $30 \mathrm{SNK}$, which were indicated to contain mesopores with diverse shapes, including bottle-necks, wedges, etc. The increase in $\mathrm{SiO}_{2}$ content resulted in mesopores of diverse shape after the HF treatment. The width of the isotherm hysteresis loop gradually increased in proportion to the amount of $\mathrm{SiO}_{2}$ template used $[17,18]$.

The textural properties of novolac-type phenol-based activated carbon extracted from the Brunauer-Emmett-Teller

\section{Table 1. Textural properties of phenol-based activated carbons with hierarchical pore structure}

\begin{tabular}{cccccc} 
Sample & $\mathrm{SSA}\left(\mathrm{m}^{2} / \mathrm{g}\right)$ & $\mathrm{V}_{\mathrm{t}}\left(\mathrm{cm}^{3} / \mathrm{g}\right)$ & $\mathrm{V}_{\text {mic }}\left(\mathrm{cm}^{3} / \mathrm{g}\right)$ & $\mathrm{V}_{\text {mes }}\left(\mathrm{cm}^{3} / \mathrm{g}\right)$ & $\mathrm{R}_{\text {mes }}(\%)$ \\
\hline $\mathrm{CN}$ & 1 & - & - & - & - \\
5SNK & 947 & 0.47 & 0.39 & 0.08 & 17 \\
15SNK & 1343 & 0.78 & 0.54 & 0.24 & 31 \\
30SNK & 592 & 0.69 & 0.18 & 0.51 & 74 \\
\hline
\end{tabular}

SSA: Brunauer-Emmett-Teller specific surface area, $\mathrm{V}_{\mathrm{t}}$ : total pore volume of nitrogen adsorbed, $\mathrm{V}_{\text {mic: }}$ micropore volume calculated using the T-plot method, $V_{\text {mes: }}$ mesopore volume (total pore volume - micropore volume), $R_{\text {mes: }}$ mesopore volume ratio. 


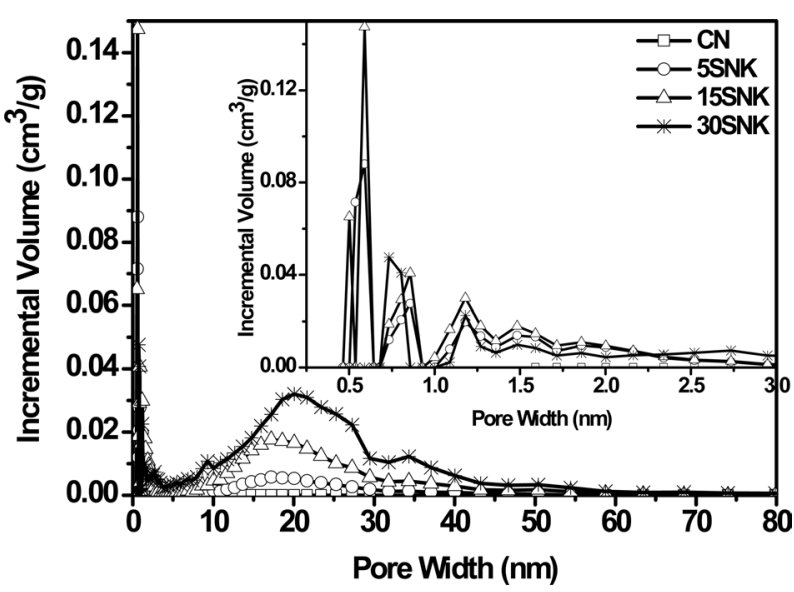

Fig. 3. Density functional theory pore size distribution of phenolbased activated carbons.

(BET) equation and the T-plot method are listed in Table 1. The specific surface area of CN $\left(1 \mathrm{~m}^{2} / \mathrm{g}\right), 5 \mathrm{SNK}\left(947 \mathrm{~m}^{2} / \mathrm{g}\right)$ and $15 \mathrm{SNK}\left(1343 \mathrm{~m}^{2} / \mathrm{g}\right)$ increased with increaseing $\mathrm{SiO}_{2}$ content, whereas that of 30SNK $\left(592 \mathrm{~m}^{2} / \mathrm{g}\right)$ decreased under similar circumstances. The micropores provide a high surface area. Additionally, the $\mathrm{SiO}_{2}$ caused aggregation and resulted in less-developed micropores after $\mathrm{KOH}$ activation because of a decrease in the number of active sites in the case of 30 $\mathrm{SNK}$. The well-dispersed $\mathrm{SiO}_{2}$ generated numerous active sites after the HF treatment and reaction $\mathrm{KOH}$. Thus, 30SNK was activated inefficiently by $\mathrm{KOH}$ and contained less-developed micropores, whereas the number of micropores in 5SNK and $15 \mathrm{SNK}$ increased. However, the mesopore volume of all the samples increased with increasing $\mathrm{SiO}_{2}$ content. These results indicate that the amount of $\mathrm{SiO}_{2}$ was an important factor for pore properties.

Fig. 3 shows the pore size distributions of the prepared samples before and after physical and chemical activation, as calculated via the density functional theory method. Micropores smaller than $3 \mathrm{~nm}$ developed extensively in $15 \mathrm{SNK}$, and the other samples have a similar range of micropores, with little difference in pore volume after KOH activation [19]. However, in 30SNK, mesopores between 5 and $50 \mathrm{~nm}$ were mostly formed as a consequence of $\mathrm{SiO}_{2}$, aggregation; the mesopore sizes of the other samples decreased in the order $15 \mathrm{SNK}>5 \mathrm{SNK}>\mathrm{CN}$. In all of the samples, the most common mesopore size was 15-20 $\mathrm{nm}$.

\subsection{Electrochemical properties of phenol- based activated carbon with hierarchical pore structure}

Fig. 4 provides the $\mathrm{CV}$ of the novolac-type phenol-based activated carbon within a potential range of $0-1.0 \mathrm{~V}$ at scan rates of 5 and $50 \mathrm{mV} / \mathrm{s}$. At a scan rate of $5 \mathrm{mV} / \mathrm{s}$ (Fig. $4 \mathrm{a}$ ), the shapes of the $\mathrm{CV}$ profiles of the samples were approximately rectangular, and redox peaks were observed at 0.3-0.4 V. At the higher scan rate (i.e., $50 \mathrm{mV} / \mathrm{s}$ ), the profiles became gradually depressed (Fig. 4b). We attributed such tilted rectangular shapes to the influence of the ohmic resistance from
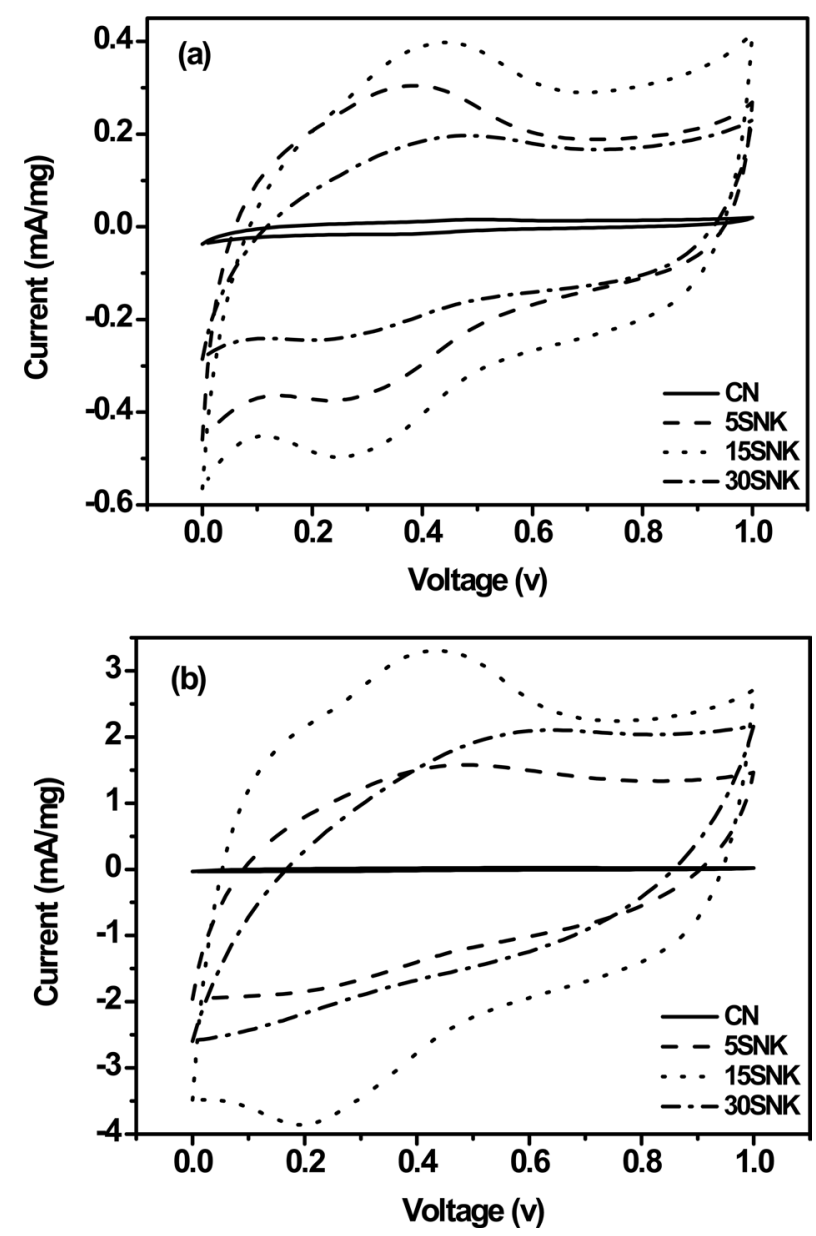

Fig. 4. Cyclic voltammograms of electrodes fabricated from activated carbons with hierarchical-pore structures; the voltammograms were obtained at scan rates of $5 \mathrm{mV} / \mathrm{s}(\mathrm{a})$ and $50 \mathrm{mV} / \mathrm{s}(\mathrm{b})$.

the electrolyte motion in the carbon pores upon double-layer formation [20]. These rectangular shapes likely arise because the ions can transport into pores more easily at a low scan rate than at a high scan rate $[21,22]$. This phenomenon was prevalent in $\mathrm{CN}, 5 \mathrm{SNK}$, and 30SNK, though minimally in $15 \mathrm{SNK}$. We interpreted these results as indicating that the coexistence of micropores and mesopores with a high specific surface area provides ion accessibility to an electrode surface at a wide range of scan rates.

The specific capacitances of the prepared EDLCs are shown in Table 2. The 15SNK exhibited a higher specific capacitance at both scan rates ( 5 and $50 \mathrm{mV} / \mathrm{s}$ ) compared to those of the other samples. The specific capacitances of $15 \mathrm{SNK}$ were 113 and $90 \mathrm{~F} / \mathrm{g}$ at scan rates of 5 and $50 \mathrm{mV} / \mathrm{s}$, respectively. 30SNK exhibited the highest retained capacitance ratio; however, its specific capacitances of 56 and $48 \mathrm{~F} / \mathrm{g}$ at scan rates of 5 and $50 \mathrm{mV} / \mathrm{s}$, respectively, were lower than expected. These results indicate that $31 \%$ of the mesopore volume ratio is appropriate for both improved specific capacitance and retained capacitance ratio. A greater mesopore volume ratio results in decreased specific surface area and specific capacitance. The highest specific capacitances and greatest enhanced retained capacitance ratio 
Table 2. The specific capacitances of phenol-based activated carbon electrodes at scan rates of 5 and $50 \mathrm{mV} / \mathrm{s}$

\begin{tabular}{cccc}
\multirow{2}{*}{ Sample } & \multicolumn{2}{c}{ Specific capacitance $(\mathrm{F} / \mathrm{g})$} & $\begin{array}{c}\text { Retained } \\
\text { capacitance } \\
\text { ratio (\%) }\end{array}$ \\
\cline { 2 - 3 } At $5 \mathrm{mV} / \mathrm{s}$ & At $50 \mathrm{mV} / \mathrm{s}$ & 25 \\
CN & 4 & 1 & 70 \\
$5 \mathrm{SNK}$ & 83 & 58 & 80 \\
$15 \mathrm{SNK}$ & 113 & 90 & 86 \\
$30 \mathrm{SNK}$ & 56 & 48 & \\
\hline
\end{tabular}

were observed in the case of $15 \mathrm{SNK}$. Therefore, increases in the micropore volume, mesopore volume, and specific surface area resulted in a higher specific capacitance and enhanced retained capacitance ratio, suggesting considerably improved EDLC performance.

\section{Conclusion}

In this study, phenol-based activated carbon with a hierarchical pore structure was prepared by physical and chemical activation using a $\mathrm{SiO}_{2}$ template and $\mathrm{KOH}$; the activated carbon was designed for enhanced EDLC performance. By studying the morphology of the activated carbon with a hierarchical pore structure, we observed that the roughness of the surface of the activated carbon increases with increasing $\mathrm{SiO}_{2}$ content, as determined via SEM observations. The BET specific surface area and micropore volume of $15 \mathrm{SNK}$ were the highest among the tested samples: $1343 \mathrm{~m}^{2} / \mathrm{g}$ and $0.54 \mathrm{~cm}^{3} / \mathrm{g}$, respectively. For all of the samples, the mesopore volume increased approximately $74 \%$ when the $\mathrm{SiO}_{2}$ content was increased. In the case of $30 \mathrm{SNK}$, its specific surface area decreased despite having the highest $\mathrm{SiO}_{2}$ content due to the aggregation of $\mathrm{SiO}_{2}$. Through CV, we confirmed that the developed micropores and mesopores with high specific surface area improved the specific capacitance of the resultant activated carbon electrode even at high scan rates: 113 and $90 \mathrm{~F} / \mathrm{g}$ at scan rates of 5 and $50 \mathrm{mV} / \mathrm{s}$, respectively. Additionally, the retained capacitance ratio of $15 \mathrm{SNK}$ was enhanced compared to those of $\mathrm{CN}$ and 5 SNK. Therefore, physical and chemical activation using a $\mathrm{SiO}_{2}$ template and $\mathrm{KOH}$ is an effective method for improving the specific capacitance and retained capacitance ratio of activated carbons.

\section{References}

[1] Burke A. Ultracapacitors: why, how, and where is the technology. J Power Sources, 91, 37 (2000). http://dx.doi.org/10.1016/S03787753(00)00485-7.

[2] Im JS, Park SJ, Lee YS. Preparation and characteristics of electrospun activated carbon materials having meso- and macropores. J Colloid Interface Sci, 314, 32 (2007). http://dx.doi.org/10.1016/j. jcis.2007.05.033.

[3] Wang YS, Wang CY. Templated mesoporous carbons and their performance for electric double layer capacitors. New Carbon Mater
25, 376 (2010). http://dx.doi.org/10.1016/S1872-5805(09)60041$\mathrm{X}$.

[4] Nakagawa K, Mukai SR, Tamura K, Tamon H. Mesoporous activated carbons from phenolic resins. Chem Eng Res Des, 85, 1331 (2007). http://dx.doi.org/10.1205/cherd06119.

[5] Fuertes AB, Sevilla M, Alvarez S, Valdes-Solís T. Control of the structural properties of mesoporous polymers synthesized using porous silica materials as templates. Microporous Mesoporous Mater, 112, 319 (2008). http://dx.doi.org/10.1016/j.micromeso. 2007.10.004.

[6] Li Q, Jiang R, Dou Y, Wu Z, Huang T, Feng D, Yang J, Yu A, Zhao $D$. Synthesis of mesoporous carbon spheres with a hierarchical pore structure for the electrochemical double-layer capacitor. Carbon, 49, 1248 (2011). http://dx.doi.org/10.1016/j.carbon.2010.11.043.

[7] Kao LH, Hsu TC. Silica template synthesis of ordered mesoporous carbon thick films with 35-nm pore size from mesophase pitch solution. Mater Lett, 62, 695 (2008). http://dx.doi.org/10.1016/j. matlet.2007.06.034.

[8] Cabañas A, Enciso E, Carmen Carbajo M, Torralvo MJ, Pando C, Renuncio JAR. Studies on the porosity of $\mathrm{SiO}_{2}$-aerogel inverse opals synthesised in supercritical $\mathrm{CO}_{2}$. Microporous Mesoporous Mater, 99, 23 (2007). http://dx.doi.org/10.1016/j.micromeso.2006.08.030.

[9] Lee D, Cho S, Kim Y, Lee YS. Influence of the pore properties on carbon dioxide adsorption of PAN-based activated carbon nanofibers. Polymer (Korea), 37, 592 (2013). http://dx.doi.org/10.7317/ pk.2013.37.5.592.

[10] Kim YJ, Horie Y, Matsuzawa Y, Ozaki S, Endo M, Dresselhaus MS Structural features necessary to obtain a high specific capacitance in electric double layer capacitors. Carbon, 42, 2423 (2004). http:// dx.doi.org/10.1016/j.carbon.2004.04.039.

[11] Yoon SH, Lim S, Song Y, Ota Y, Qiao W, Tanaka A, Mochida I. $\mathrm{KOH}$ activation of carbon nanofibers. Carbon, 42, 1723 (2004) http://dx.doi.org/10.1016/j.carbon.2004.03.006.

[12] Sing KSW, Everett DH, Haul RAW. Moscou L, Pierotti RA, Rouquérol J, Siemieniewska T. Reporting physisorption data for gas/ solid systems with special references to the determination of surface areas and porosity. Pure Appl Chem, 57, 603 (1985). http:// dx.doi.org/10.1351/pac198557040603.

[13] Youssef AM, Hassan AF, Safan M. Modeling and characterization of steam-activated carbons developed from cotton stalks, Carbon Lett, 14, 14 (2013). http://dx.doi.org/10.5714/CL.2012.14.1.014.

[14] Bai BC, Kim JG, Im JS, Jung SC, Lee YS. Influence of oxyfluorination on activated carbon nanofibers for $\mathrm{CO}_{2}$ storage. Carbon Lett, 12, 236 (2011). http://dx.doi.org/10.5714/CL.2011.12.4.236.

[15] Jung MJ, Jeong E, Lee SI, Lee YS. Improved capacitance characteristics of activated carbon-based electrodes by physicochemical base-tuning. J Ind Eng Chem, 18, 642 (2012). http://dx.doi. org/10.1016/j.jiec.2011.11.055.

[16] Lee HM, Kang HR, An KH, Kim HG, Kim BJ. Comparative studies of porous carbon nanofibers by various activation methods. Carbon Lett, 14, 180 (2013). http://dx.doi.org/10.5714/CL.2013.14.3.180.

[17] Kim Y, Cho S, Lee S, Lee YS. Fabrication and characterization of porous non-woven carbon based highly sensitive gas sensors derived by magnesium oxide. Carbon Lett, 13, 254 (2012). http:// dx.doi.org/10.5714/CL.2012.13.4.254.

[18] Han S, Lee KT, Oh SM, Hyeon T. The effect of silica template structure on the pore structure of mesoporous carbons. Carbon, 41, 1049 (2003). http://dx.doi.org/10.1016/S0008-6223(02)00439-6. 
[19] Kim DW, Park SJ. Effect of potassium permanganate pretreatment of pitch on the textural properties of pitch-based activated carbons. Carbon Lett, 12, 167 (2011). http://dx.doi.org/10.5714/ CL.2011.12.3.167.

[20] Xia X, Shi L, Liu H, Yang L, He Y. A facile production of microporous carbon spheres and their electrochemical performance in EDLC. J Phys Chem Solids, 73, 385 (2012). http://dx.doi. org/10.1016/j.jpcs.2011.10.028.
[21] Zeng X, Wu D, Fu R, Lai H. Structure and EDLC characteristics of pitch-based carbon aerogels. Mater Chem Phys, 112, 1074 (2008). http://dx.doi.org/10.1016/j.matchemphys.2008.07.038.

[22] Liu G, Kang F, Li B, Huang Z, Chuan X. Characterization of the porous carbon prepared by using halloysite as template and its application to EDLC. J Phys Chem Solids, 67, 1186 (2006). http:// dx.doi.org/10.1016/j.jpcs.2006.01.044. 